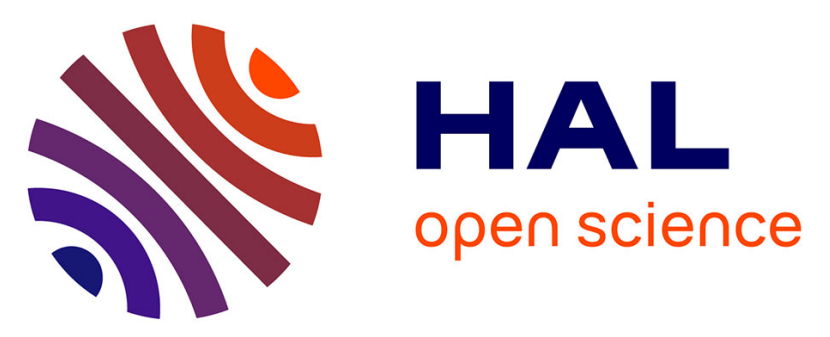

\title{
Landscape floral resources provided by rapeseed correlate with next-year reproduction of cavity-nesting pollinators in a national participatory monitoring program
}

Victor van Der Meersch, Olivier Billaud, Magali San Cristobal, Aude Vialatte, Emmanuelle Porcher

\section{To cite this version:}

Victor van Der Meersch, Olivier Billaud, Magali San Cristobal, Aude Vialatte, Emmanuelle Porcher. Landscape floral resources provided by rapeseed correlate with next-year reproduction of cavitynesting pollinators in a national participatory monitoring program. Landscape Ecology, 2022, 10.1007/s10980-021-01353-0 . hal-03407457

\section{HAL Id: hal-03407457 \\ https://hal.science/hal-03407457}

Submitted on 28 Oct 2021

HAL is a multi-disciplinary open access archive for the deposit and dissemination of scientific research documents, whether they are published or not. The documents may come from teaching and research institutions in France or abroad, or from public or private research centers.
L'archive ouverte pluridisciplinaire HAL, est destinée au dépôt et à la diffusion de documents scientifiques de niveau recherche, publiés ou non, émanant des établissements d'enseignement et de recherche français ou étrangers, des laboratoires publics ou privés. 


\title{
Landscape floral resources provided by rapeseed correlate with next-year reproduction of cavity-nesting pollinators in a national participatory monitoring program
}

\author{
Victor Van der Meersch · Olivier \\ Billaud · Magali San Cristobal · Aude \\ Vialatte · Emmanuelle Porcher . \\ 8 Received: date / Accepted: date
}

Abstract Context Wild pollinators depend on floral resources available in the landscape, partly provided by mass flowering crops (MFCs), such as rapeseed or sunflower. MFCs are however often grown conventionally, implying insecticide use, with potential negative effects on pollinators.

Objectives To understand whether and to what extent these crops could contribute to the maintenance of pollinator populations, we investigated the

Grants or other notes about the article that should go on the front page should be placed here. General acknowledgments should be placed at the end of the article.

Victor Van der Meersch

Centre d'Ecologie et des Sciences de la Conservation (CESCO), Muséum national d'Histoire naturelle, Centre National de la Recherche Scientifique, Sorbonne Université, Paris, France

Olivier Billaud

Centre d'Ecologie et des Sciences de la Conservation (CESCO), Muséum national d'Histoire naturelle, Centre National de la Recherche Scientifique, Sorbonne Université, Paris, France

Magali San Cristobal

Dynamique et Ecologie des Paysages Agriforestiers (DYNAFOR), Institut national de recherche pour l'agriculture, l'alimentation et l'environnement, Université de Toulouse, Castanet Tolosan, France

Aude Vialatte

Dynamique et Ecologie des Paysages Agriforestiers (DYNAFOR), Institut national de recherche pour l'agriculture, l'alimentation et l'environnement, Université de Toulouse, Castanet Tolosan, France

Emmanuelle Porcher

Centre d'Ecologie et des Sciences de la Conservation (CESCO), Muséum national d'Histoire naturelle, Centre National de la Recherche Scientifique, Sorbonne Université, Paris, France E-mail: emmanuelle.porcher@mnhnfr 
inter-annual correlation between MFC resources and the reproduction of cavitynesting pollinators (solitary bees and wasps) at a national scale.

Methods We studied a standardized citizen science dataset, in which farmers collected data on the abundance of sealed tubes in trap nests, between 2012 and 2017, in nearly 600 fields distributed across France. We modelled the relation between nesting and landscape resources of the current and previous year, taking local farming practices into account.

Results Pollinator nesting was positively correlated with the quantity of rapeseed floral resources the year preceding observations, as well as with the area of permanent meadows. On the contrary, we found more variable relations with sunflower floral resources, depending on the type of sealing material, hence likely on the phenology of pollinators. Our models also confirm that local practices should be accounted for when assessing the influence of the landscape context, although their effects were difficult to interpret.

Conclusions That solitary bee and wasp reproduction is likely to be positively and durably affected by rapeseed cover. Moderate areas of rapeseed may help maintaining pollinators, in combination with semi-natural habitats, which provide more diverse and stable food and nesting sites.

Keywords agriculture; · biodiversity; · citizen science; · Osmia; · solitary bees; · pollination; · floral resources; · mass-flowering crops

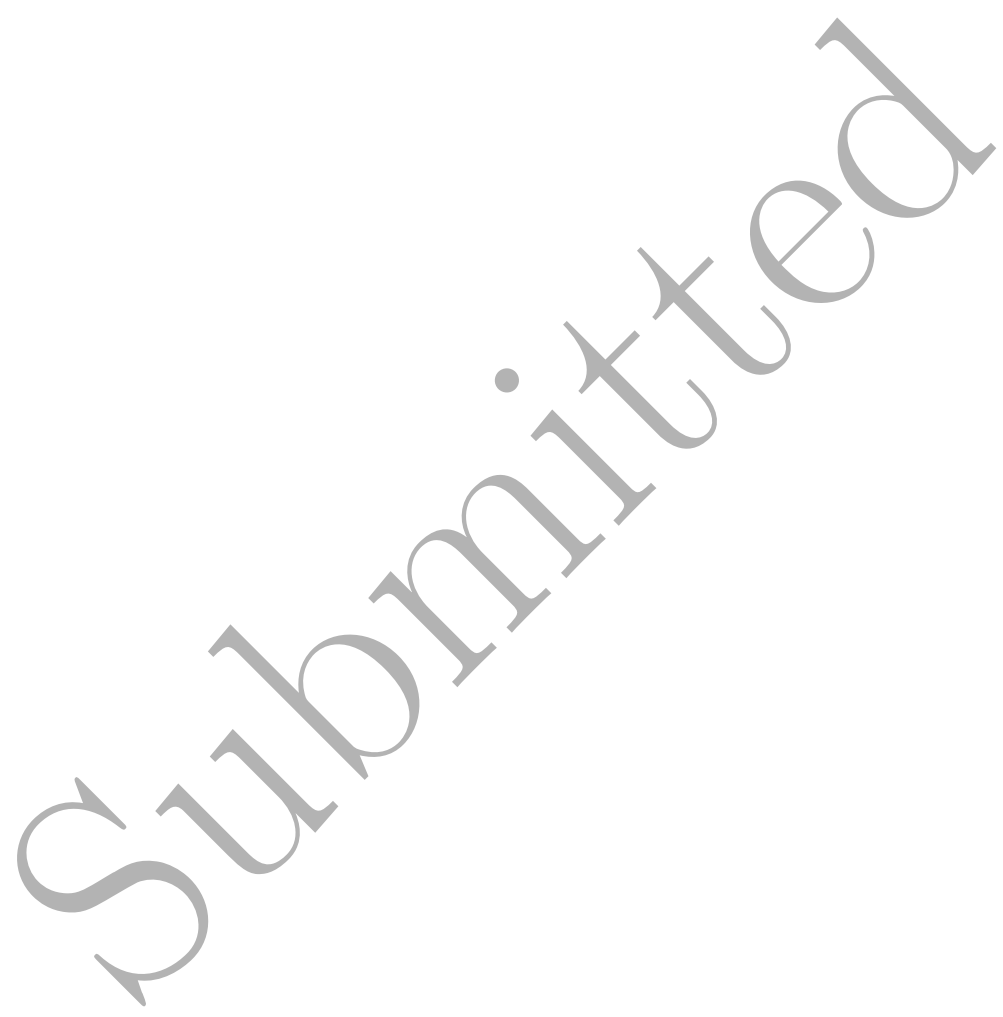


Agriculture and biodiversity are inter-linked. The observed trend toward the intensification of farming practices and the homogenization of landscapes over the past decades have triggered significant negative impacts on insect diversity and abundance (Benton et al. 2002; Sánchez-Bayo and Wyckhuys 2019). In particular, pollinators are known to decline because of several human-related drivers, including habitat loss and use of agrochemicals (Potts et al. 2010; Vanbergen and the Insect Pollinators Initiative 2013). This major loss of insects could have negative effects on ecosystem functioning, as insects play a central role in a variety of processes, including pollination: $80 \%$ of wild plants are estimated to depend on animals for pollination (Ollerton, Winfree, and Tarrant 2011), and 35\% of global agricultural production comes from crops that depend on pollinators (Klein et al. 2007). In turn, many pollinator species depend at least partially on floral resource availability and accessibility (Potts et al. 2003). The spatial and temporal distribution of floral resources is therefore essential for pollinators, especially for central place foragers such as wild bees, which are not spared from human disturbance (Biesmeijer et al. 2006; Goulson, Lye, and Darvill 2008; Potts et al. 2010; Burkle, Marlin, and Knight 2013; Woodcock et al. 2016) and cannot follow the seasonality of flowering from one area to another. They may be more efficient pollinators of wild plants and crops than honeybees (Garibaldi et al. 2014; Mallinger and Gratton 2015), and thus important for supporting pollinator-dependent crops and sustaining pollination services in agricultural areas.

In agricultural landscapes, floral resources for pollinators are provided both by wild plants and by mass flowering crops (MFCs): the former provide less abundant but more constant resources than crops, while the latter provide massive amounts of resources but during a restricted period of flowering. Although wild bees seem to depend more on wild floral resources than on MFCs (Rollin et al. 2013), many of them, including solitary bees, are still known to use MFCs (Jauker, Bondarenko, et al. 2012; Le Féon et al. 2013). Besides, the balance between positive and negative effects of MFCs on wild bees remains unclear. On the one hand, MFCs provide both pollen and nectar resources that positively affect solitary bee species richness (Diekötter et al. 2014), abundance (Le Féon et al. 2013; Riedinger et al. 2015) and reproduction (Holzschuh et al. 2012; Jauker, Peter, et al. 2012), even though some studies found a negative effect (Holzschuh et al. 2016; Shaw et al. 2020). On the other hand, MFCs are often associated with intensive agriculture, which comes with a simplification of landscapes, including fewer semi-natural landscape elements providing cavities for nesting, as well as more frequent use of pesticides, which may have lethal and sublethal effects on solitary bees (Biddinger 2013; Artz and PittsSinger 2015; Rundlöf et al. 2015; Sgolastra et al. 2017; Azpiazu et al. 2019). Moreover, by fayoring generalist pollinators, a high proportion of MFCs in the landscape may disrupt local plant-pollinator interactions (Diekötter et al. 2010). 
The observed contrasting relationships between MFCs and solitary bee abundance or reproduction may be due in part to various sources of heterogeneity in the aforementioned studies, which we aim to control in the current study. First, these studies were performed in a variety of contexts, in terms of landscape structure, farming practices or climate. In order to generalize the actual role of MFCs, we here analyse a unique dataset obtained across a wide range of agro-environmental contexts. Second, to characterize the effects of MFCs, most researchers studied either (1) immediate impacts, wherein MFCs generally attract bees or other pollinators, with sometimes a positive effect on breeding (Holzschuh et al. 2012, Le Féon et al. 2013, and Diekötter et al. 2014) or (2) year-to-year effects, wherein MFCs may influence bee abundance the following year (Jauker, Peter, et al. 2012 and Riedinger et al. 2015). Only inter-annual effects of MFCs on the fitness of wild pollinators and their population growth rate would promote their maintenance in the long term. Understanding the balance between positive effects, through the delivery of floral resources, and negative effects, through possible pesticide contamination, according to agro-environmental contexts is necessary to inform future agro-ecological management of these crops.

This study investigates the relationship between the reproduction of cavitynesting pollinators (solitary bees, but also wasps) and mass-flowering crop cover over a whole country. Our goal is to complement previous studies, on the one hand by examining year-to-year effects to assess the long term impact of MFCs, and on the other hand by considering a broad area and a variety of contexts. Our originality is to rely on a citizen science program with a large number of sites (nearly 600 fields) all over France. We focus on immediate and year-to-year landscape correlations with bee or wasp reproduction. We aimed to assess whether the cover of two widespread MFCs (rapeseed and sunflower) was correlated with solitary bee and wasp nesting both in the year of monitoring and in the following year, and thus might be able to support pollinator populations through time.

\section{Material and methods}

\subsection{Participatory monitoring of solitary bees in field edges}

The study was condueted in fields monitored by farmers all over mainland France between 2012 and 2017, within the framework of the Farmland Biodiversity Observatory (FBO). The FBO targets several taxonomic groups to identify farming practices and landscape elements that promote farmland biodiversity (Billaud, Vermeersch, and Porcher 2020). To our knowledge, this is one of the first national biodiversity monitoring programs to use a participatory approach involving farmers. Over a total of 1,501 sites, we selected 576 sites, including 416 field crops and 166 meadows, for which all required environmental variables (see below), including geographical coordinates, were well

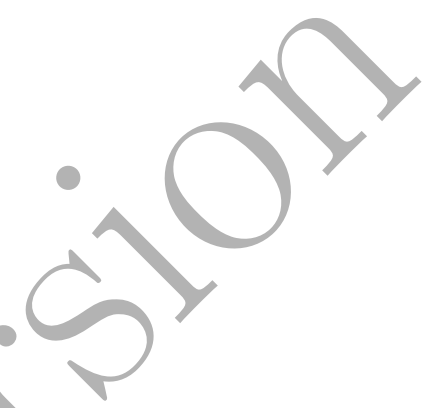


reported. Some sites were monitored several years in a row (see below for more details).

\subsection{Trap nests in field boundary}

All farmers set up two standardized trap nests 5 meter away from each other in each studied field boundary. A trap nest consisted of 32 cardboard tubes that were fixed facing south, on a wooden post, 1 meter above the ground (Billaud, Vermeersch, and Porcher 2020). Farmers monitored nest occupancy, an indicator for reproductive performance, by counting sealed tubes. They also reported a proxy for the diversity of nesting species by identifying the sealing material (mud, chewed leaves, trichomes of woolly plants...). Theoretically, trap nests were meant to be monitored once a month between March and November, but some observers tended to forget some of the surveys. Within a year, $91.8 \%$ of sites were sampled at least twice, and $49 \%$ at least five times. Accordingly, we did not summarize data within a year, but chose to use all 3,345 observations, i.e. one count in a given month per trap nest. Note, however, that other analysis choices, such as considering the maximum number of sealed tubes within a year, did not modify the main results (not shown).

We focused our study on both total abundance (pooling all sealing materials) and abundance of the most abundant category of sealing material, i.e. mud, which represents $65 \%$ of observations. These mud-sealed tubes are likely to be made in great part by Osmia bees (Linsley 1958), which are early spring foragers. We therefore expect them to benefit more from the presence of rapeseed than from that of sunflower. However, this prediction should be considered with caution because other cavity-nesting, flower-visiting taxa such as some Megachile (e.g. subgenus Chalicodoma, see Micheney 2007), and solitary wasps such as Eumeninae, Sphecidae and Crabponidae (Steffan-Dewenter and Leschke 2003; Pereira-Peixoto et al. 2014, MacIvor and Packer 2015), may also use mud for nest building.

\subsection{Environmental variables}

Landscape variables We used the national cartographic field registry (Registre parcellaire graphique, RPG) to map each crop type within a buffer around each study site. We chose the size of the buffer a priori on the basis of ecological knowledge of solitary bees instead of testing multiple spatial extents and taking the one that best predicts the response, because the latter approach is sometimes biased (Jackson and Fahrig 2015). The area of each crop in the buffer was calculated using the R package $s f$ (Pebesma 2018).

We computed the area of the two main MFCs (rapeseed and sunflower) both in the sampling year and the previous year. For the sampling year calculation, we used a $250 \mathrm{~m}$-radius buffer since the distance at which half of the population discontinues foraging (few hundred meters) is more relevant than

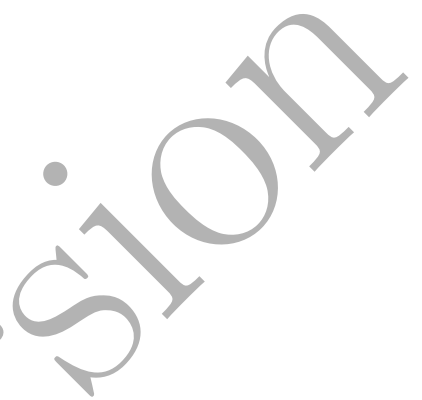


the species specific maximum foraging distance (Zurbuchen et al. 2010). For the previous year calculation, we decided to use a $1000 \mathrm{~m}$-radius buffer because the dispersal distance, from the emergence site to the nesting site, is larger than the median foraging distance of solitary bees and wasps. We chose the buffer sizes according to the measurements by Zurbuchen et al. (2010) for two species of the Osmiini tribe with different sizes (Hylaeus punctulatissimus and Hoplitis adunca), as a proxy for the foraging and dispersal distances of all pollinators visiting the trap nests. However, the choice of the buffer radius $(250 \mathrm{~m}$ or $1,000 \mathrm{~m}$ ) for the area of MFCs the year preceding the observation did not influence the results (not shown).

In order to take into account all other floral resources beyond crops and nesting opportunities, we also computed the area of temporary meadows for both sampling year and previous year and the area of orchards and permanent meadows in the sampling year only (because these land uses change little through time). We followed the definition of the Common Agricultural Policy of the European Union to differentiate permanent ( 5 years or more) vs. temporary meadows ( $\leq 4$ years). Finally, as forest margins are known to influence wild bees (Bailey et al. 2014; Joshi et al. 2016; Odanaka and Rehan 2020), we also computed the perimeter of forests in the buffer using the Corine Land Cover database provided by the European Environmental Agency.

Local variables For each field, farmers reported the presence of surrounding linear elements: hedgerows and their age (old vs. young, a qualitative assessment at the discretion of the observer), grass strips, roads, ditches, woody margins. They were used in the models below to inform on potential food sources next to the trap nests. We characterized farming practices with two classes on the basis of farmers' reporting. For nesting observations located in a meadow edge, we used the type of meadow (temporary vs. permanent). For nesting observations located in a field crop edge, we used the farming system (conventional vs. organic farming).

Control variables We assessed local weather conditions with the E-OBS database from the European Climate Assessment Dataset project (Cornes et al. 2018). Spring weather conditions influence the phenology of early solitary bees and wasps that can forage on rapeseed (Vicens and Bosch 2000), on the one hand, and the flowering period of rapeseed and the sowing date of sunflower, on the other hand. For each monitored field, we chose to compute the mean temperature and the sum of precipitation between the $20^{\text {th }}$ of February and either the $31^{\text {st }}$ of May or the sampling date, whichever came first. Since we did not know the exact nest installation date, we also included the number of days between the beginning of the year and the observation date as a proxy for the period of time during which a nest is installed. These three variables (mean temperature, sum of precipitation and time) were included in the model below as control variables, i.e. we checked that their effect was consistent with expectations. 


\subsection{Statistical analysis}

The correlations between landscape resources and the presence/absence and abundance of sealed tubes in trap nests were assessed using two hurdle mixed models, one for each field edge type (field crop and meadow), in R ( $\mathrm{R}$ Core Team 2020) on RStudio (RStudio Team 2019) with the glmmTMB package (Brooks et al. 2017). Hurdle models are two-stage models that provide a way of modeling the excessive proportion of zero values and are known to perform well for ecological data (Potts and Elith 2006). The first stage models the presence/absence of sealed tubes with a probability of presence $\pi$, and the second stage models their abundance, with mean $\mu$, conditional on the presence of mud-sealed tubes. Compared to zero-inflation models, a hurdle model assumes that there is a single process by which a zero can be produced.

Let $Y_{i, j, k}$ be a random variable that represents the number of sealed tubes observed during the $k^{t h}$ observation in plot $j$ of year $i$. The hurdle mixed model is the following:

$$
\begin{gathered}
\operatorname{Pr}\left\{Y_{i, j, k}=y \mid \pi_{i, j, k},\left(\theta, \mu_{i, j, k}\right)\right\}=\left\{\begin{array}{l}
1-\pi_{i, j, k}, y=0 \\
\pi_{i, j, k} \frac{N e g \operatorname{Bin}\left\{y,\left(\theta, \mu_{i, j, k}\right)\right.}{1-\operatorname{Neg} \operatorname{Bin}\left\{0,\left(\theta, \mu_{i, j, k}\right)\right.}, y>0
\end{array}\right. \\
\operatorname{logit}(\Pi)=X_{\text {zero }} * B_{\text {zero }}+S_{\text {zero }} \quad \operatorname{logit}(M)=X_{\text {count }} * B_{\text {count }}+S_{\text {count }}
\end{gathered}
$$

with $\Pi$ and $M$ vectors of probabilities $\pi_{i, j, k}$ and means $\mu_{i, j, k}, X_{z e r o}$ and $X_{\text {count }}$ vectors of fixed effects listed in Appendix A with their related vectors of coefficients $B_{\text {zero }}$ and $B_{\text {count }}, S_{\text {zero }}$ (resp $\left.S_{\text {count }}\right)$ the vector of site random intercepts $s_{j}^{\text {zero }} \sim \mathcal{N}\left(0, \sigma_{\text {zero }}^{2}\right)$ (resp. $\left.s_{j}^{\text {count }} \sim \mathcal{N}\left(0, \sigma_{\text {count }}^{2}\right)\right)$, and $\theta$ the dispersion parameter of the negative binomial.

In our models, we included five types of variables with fixed effects, which are listed in Appendix A. (1) four variables related to the quantity of floral resources provided by MFCs (area of rapeseed and sunflower in the current and previous year), (2) seven variables related to the semi-natural elements likely to provide additional floral resources and nesting opportunities in the surrounding landscape, (3) eight variables describing either local practices in the field neighbouring the monitoring site or local food/nesting sources and (4) their interactions with landscape resources, and finally (5) three control variables. We also included a site random effect to take into account the non-independence of repeated observations in some fields, within a year and between years (131 sites were monitored at least two consecutive years). All variables were standardized and centered. Note that, to avoid multicollinearity issues, we did not include the type of crop sown in the neighbouring field in the models because it was indirectly taken into account in the landscape variables. 

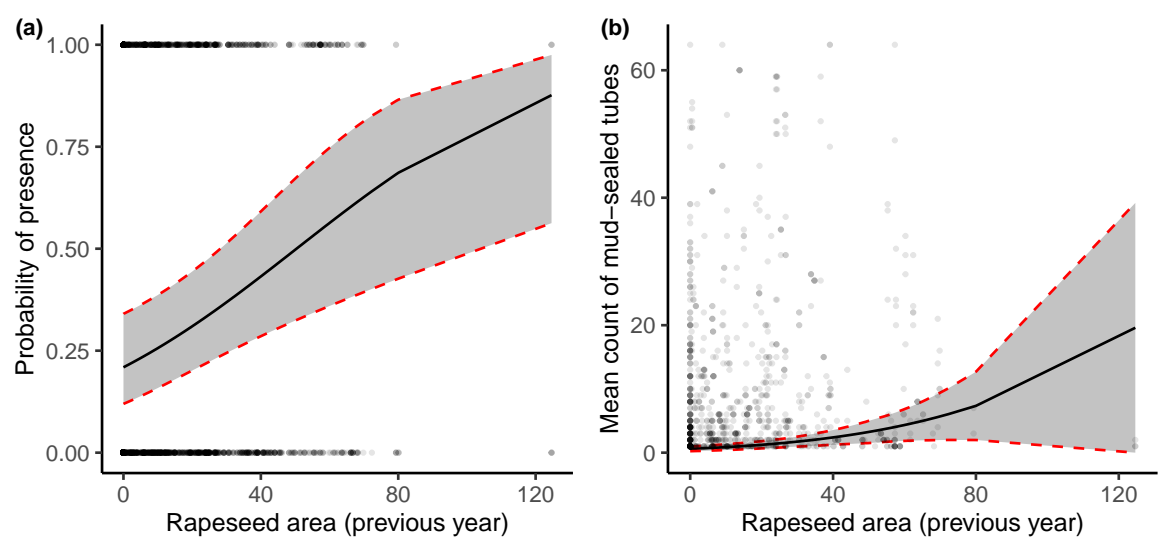

Fig. 1 Relationship between (a) probability of presence of a mud-sealed tube or (b) abundance of mud-sealed tubes, in trap nests set up in field crop edges, and rapeseed field area in the previous year. Continuous black lines are either (a) the predicted zero-inflation probability or (b) the mean model prediction conditioned on the fixed effects and the zero-inflation component. Grey ribbons are the confidence intervals. Each grey point represents one observation; multiple grey points on top of each other appear in darker grey.

We first analysed full models (see Appendix A). Then, we ran an automatic selection with the $\mathrm{R}$ package MuMIn (Barton 2020), using the corrected Akaike information criteria (AICc) and fixing several variables of interest for our main questions. Variables selected through this process are in italics in Table 1. We also checked the variance inflation factor with the $\mathrm{R}$ package performance (Lüdecke et al. 2020) to ensure there was no multicollinearity (see Appendix B). We used the DHARMa package (Hartig 2020) for residual diagnostics. Residual overdispersion and zero-inflation were acceptable upon visual inspection (see Appendix C). The Durbin-Watson test was not significant for most of the residuals, we thus decided to ignore temporal autocorrelation (see Appendix D.

Model outputs were formatted with the help of the texreg package (Leifeld 2013). Finally, we used the ggeffects package (Lüdecke 2018) to build output figures.

This workflow of data analysis was applied to two dependent variables : the number of mud-sealed tubes, representing the majority of observations, and the total number of sealed tubes. In the following, we present mostly results on mud-sealed tubes, because they are generally similar to results for all tubes and because they are likely to represent patterns for a more restricted taxonomic group. We nonetheless discuss dissimilarities between both analyses and provide full results on all tubes in Appendix E. 

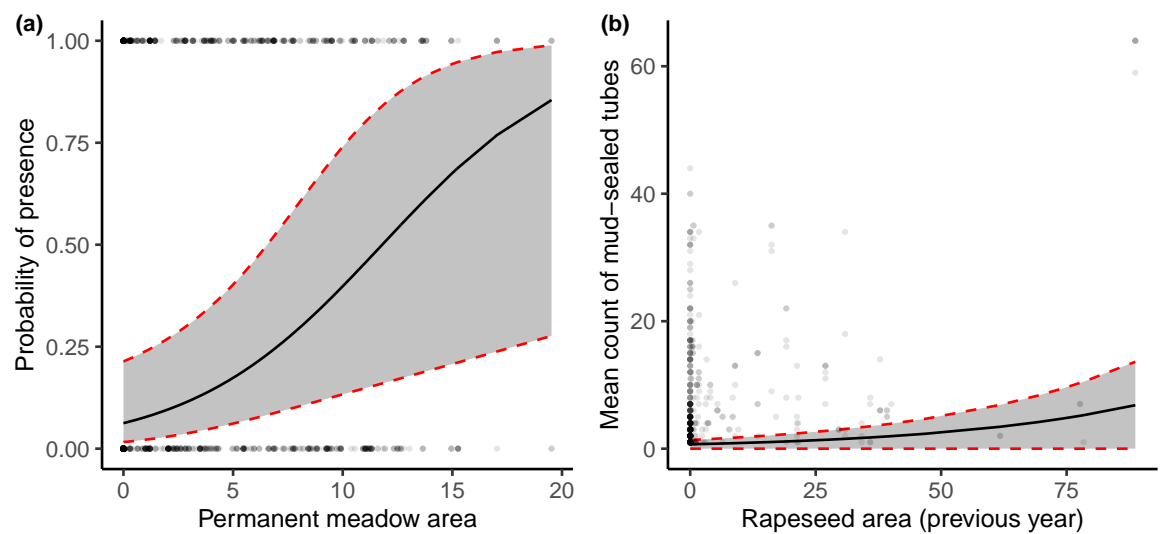

Fig. 2 Relationship between (a) probability of presence of a mud-sealed tube and permanent meadow area, or (b) abundance of mud-sealed tubes and rapeseed field area in the previous year, in trap nests set up in meadow edges. Continuous black lines are either (a) the predicted zero-inflation probability or (b) the mean model prediction conditioned on the fixed effects and the zero-inflation component. Grey ribbons are the confidence intervals. Each grey point represents one observation; multiple grey points on top of each other appear in darker grey.

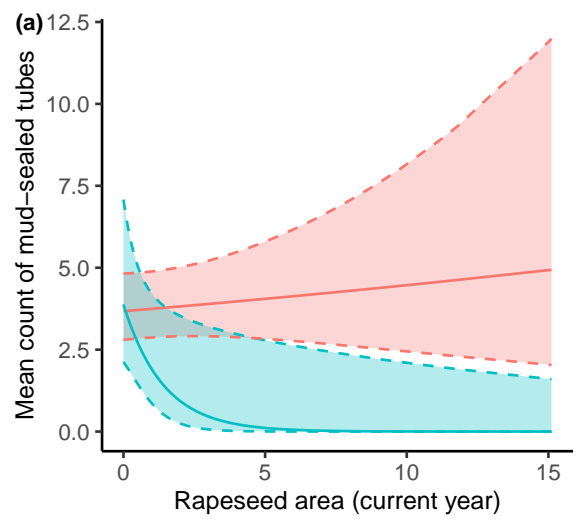

Conventional farming (b)

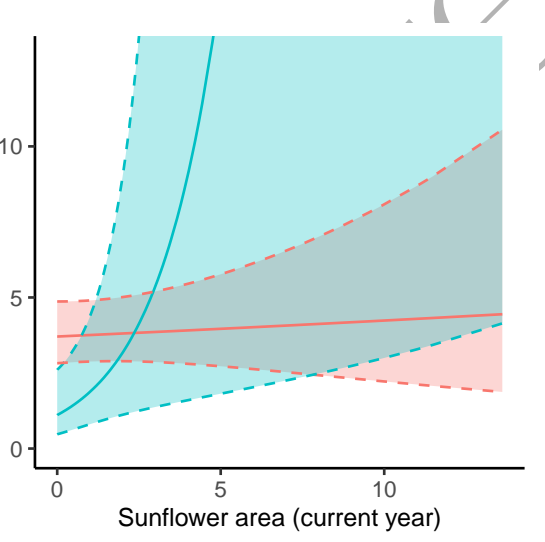

Organic farming

Fig. 3 Relationship between abundance of mud-sealed tubes and mass-flowering crop area ((a) rapeseed, or (b) sunflower), for trap nests set up in field crop edges across different farming systems. Lines are the mean model predictions, conditioned on the fixed effects and the zero-inflation component. Ribbons are the confidence intervals. 
Table 1 Output of hurdle models examining the relationship between the presence of mudsealed tubes ("Zero model") or their abundance conditional on presence ("Count model") and environmental variables. The table shows the parameter estimates, with standard errors in parentheses, after automatic selection of variables. Non-italicized variables were fixed, while italicized variables are those that were retained during the automatic selection process. Parameters with a p-value $<0.05$ are highlighted in bold. All variables were standardized and centered.

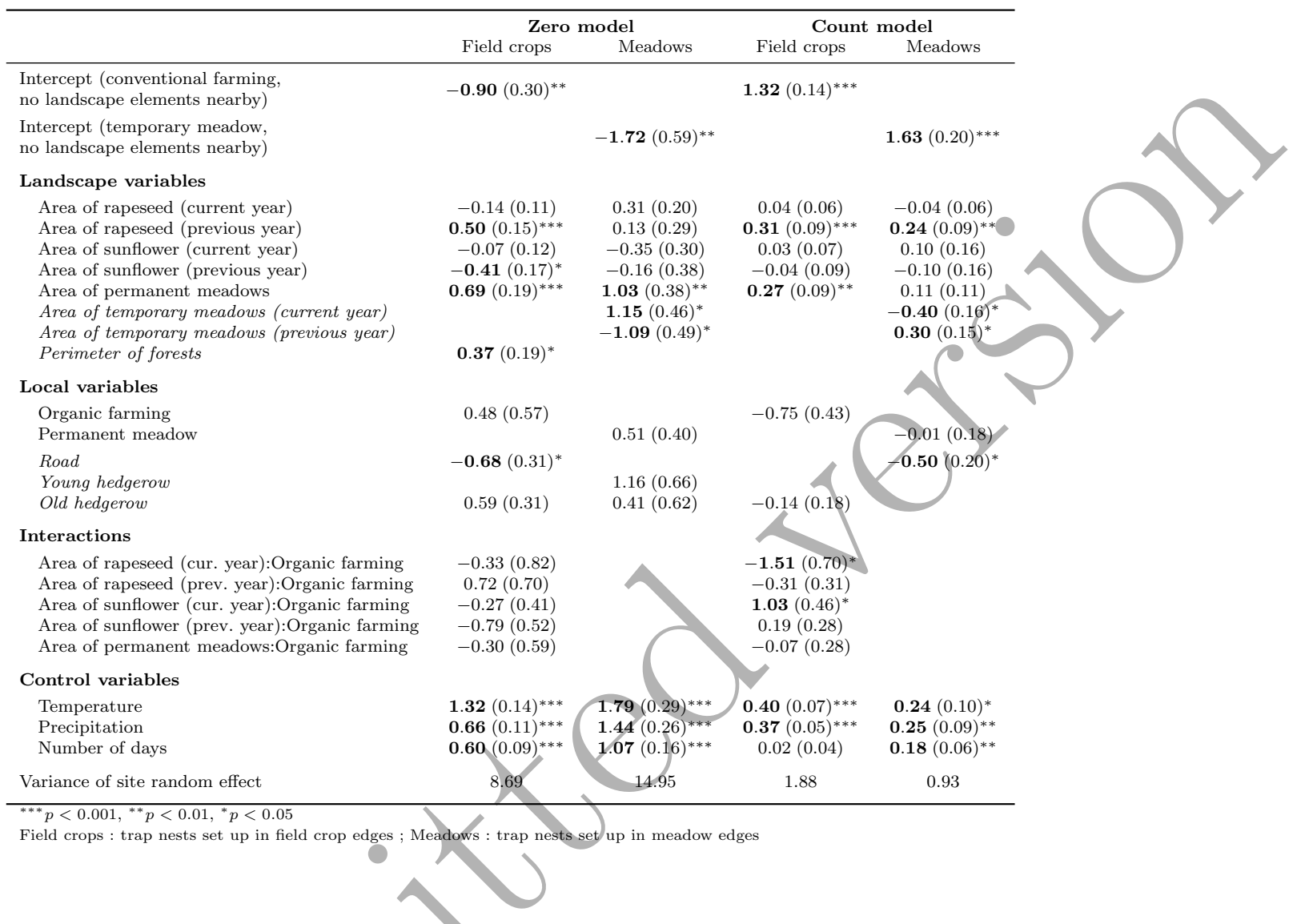

\section{Results}

3.1 Relationship between area of mass-flowering crops and reproduction of cavity-nesting pollinators

Nesting was generally positively correlated with the quantity of floral resources provided by MFCs, but the relationships depended on the type of sealing material, the identity of crops and the timing of resource availability. For rapeseed, only the area cultivated the year preceding observations was related to nesting (Table 1, area of rapeseed (previous year)). Regardless of the dependent variable, the area of rapeseed fields in the previous year was positively linked to 

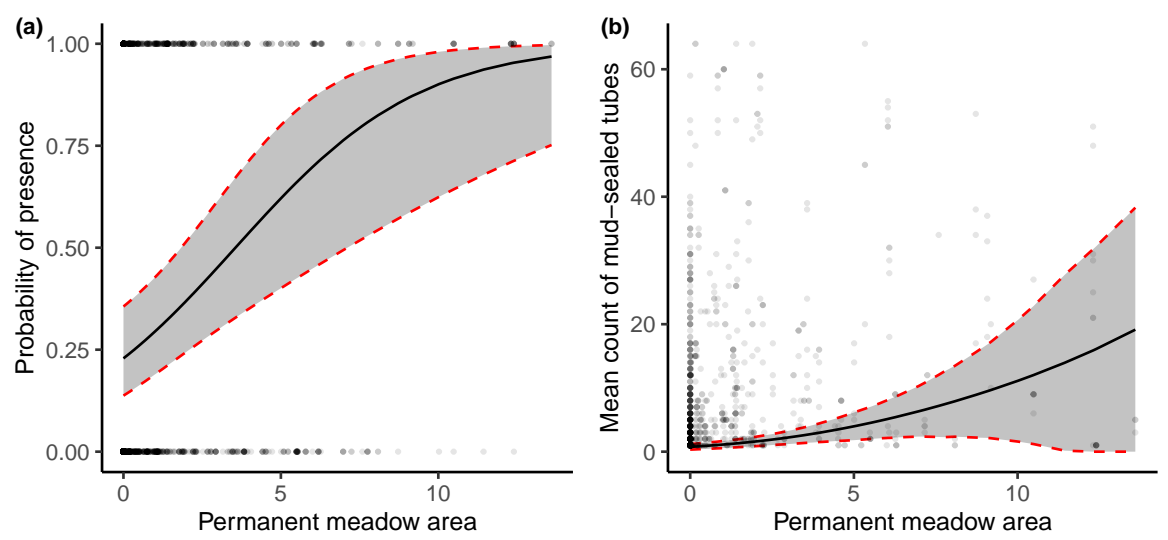

Fig. 4 Relationship between (a) probability of presence of a mud-sealed tube or (b) abundance of mud-sealed tubes, in trap nests set up in field crop edges, and permanent meadow area. Continuous black lines are either (a) the predicted zero-inflation probability or (b) the mean model prediction conditioned on the fixed effects and the zero-inflation component. Grey ribbons are the confidence intervals. Each grey point represents one observation; multiple grey points on top of each other appear in darker grey.

the abundance of occupied tubes in field crop edges (Fig. 1b) and in meadow edges (Fig. 2p). The area of rapeseed fields in the previous year was also positively related to the presence of mud-sealed tubes in field crop edges (Fig. 11a). In contrast, the area of rapeseed fields in the current year did not correlate significantly with pollinator nesting, regardless of the model (Table 1, area of rapeseed (current year)). For sunflower, field area in the previous year was negatively linked to the presence of mud-sealed tubes in field crop edges, but the area of sunflower fields in the year of observations was positively related to the presence of all types of sealing materials (Table 1, area of sunflower (previous year) and Appendix E, Table 4, area of sunflower (current year)). Similarly, in meadow edges sunflower area was positively related to the presence of occupied tubes (Appendix E, Table 4). In all other cases, there was no significant correlation of sunflower area with bee and wasp reproduction.

In addition to the simple effect of previous year MFC area on mud-sealed tubes, we observed significant interactions of current-year MFC area with the farming system, although the latter did not have a significant simple effect (Table 1, area of rapeseed (cur. year):organic farming and area of sunflower (cur. year):organic farming). These interactions differed between MFCs. With rapeseed, the relationship between mud-sealed tube abundance and coexisting crop area varied from slightly positive to negative in conventional vs. organic fields (Fig. 3 a). In contrast, with sunflower, the same relationship varied from slightly positive to strongly positive in conventional vs. organic fields (Fig. 3b). The significance of these interactions were however sensitive to the dependent variable considered (Tables 4 and 5 in Appendix E). 
3.2 Relationship between other landscape elements and reproduction of cavity-nesting pollinators

The presence and abundance of mud-sealed tubes also correlated significantly with the area of semi-natural elements likely to provide food or nesting sources (Table 1, area of permanent meadows). Both presence and abundance of occupied tubes were positively correlated with the area of permanent meadows in field crop edge (Fig. 4), regardless of the dependent variable. Similarly, in meadow edges, the presence of occupied tubes, but not their abundance, was positively linked to permanent meadow area (Fig. 2 a). Temporary meadows had more variable relationships with solitary bee and wasp reproduction. In meadow edges, temporary meadow area in the current year was positively related to the presence of mud-sealed tubes, but this area in the previous year was negatively related to the presence of mud-sealed tubes (Zero model in Table 1 . area of temporary meadows). The pattern was opposite for abundance (Count model in Table 1, area of temporary meadows). These relationships were not significant in models considering the maximum number of mud-sealed tubes or all occupied tubes (Table 4, Appendix E). The presence of occupied tubes was generally positively related to perimeter of forests in field crop edge, but the presence of hedgerows had no detectable correlation in any model. The proximity of a road was negatively related to the abundance of occupied tubes in meadow edges, and to the presence of occupied tubes in field crop edges. Finally, the type of meadow was not significantly correlated with nesting measured in meadow edges.

\subsection{Control variables}

In all models, the number of days since the beginning of the year was positively related to the presence of mud-sealed tubes. Similarly, when significant, mean temperature and sum of precipitation correlated positively with both presence and abundance of mud-sealed tubes.

\section{Discussion}

While examining the landscape and local correlates of solitary bee and wasp nest building across a whole country, we observed positive relationships with the area of landscape elements that provide resources, i.e. rapeseed, sunflower and permanent meadows. For rapeseed, this relationship was true only for the area cultivated the year preceding observations, regardless of the tubesealing material considered. For sunflower, nesting was positively linked with crop area in the current year when all sealing materials were considered, but negatively linked with crop area in the previous year when considering mudsealed tubes only. In the following we discuss the implications of our findings for the management of agricultural landscapes. 
4.1 Inter-annual impacts of mass flowering crops on nest building in solitary bees and wasps

We focused our study on the inter-annual effects of landscape floral resources on the reproduction of wild bees and wasps. We evidenced a positive correlation between rapeseed field area in the previous year and solitary bee and wasp nesting, both in the zero model and the abundance model. Such correlation suggests that rapeseed may have a lasting year-to-year impact on bee and wasp reproduction. Whereas solitary bee nest-building was previously shown to increase during the period of mass-flowering (Jauker, Peter, et al. 2012), we did not find any significant impact of the area of rapeseed of the current year. Our results indicate that the previous year resources seem to benefit more to nest-building and thus to support production of sexuals, a requirement to carry over benefits into the next season.

The next-year positive effect of rapeseed floral resources may be related to nest provisioning. Although both males and females feed on flowers, only females invest in brood care. During spring, solitary bee and wasp females collect building materials and food for the nest, where the eggs are lain in individual cells. The larvae stay in the nest throughout the summer and winter, using pollen reserves, and emerge the following spring. Reproductive success thus depends on the female's ability to provision nests with enough pollen mixture to ensure the emergence of enough offspring the following year. Trap nests only provide information about the number of sealed tubes, and not about the actual number of cells and larvae in each tube. We do not know the actual number of viable offspring that will emerge the following spring: in previous studies, it has been shown that sometimes no-adults emerge from a nest, notably because all cells can be parasitized (e.g. Steffan-Dewenter 2002). Variation in offspring number within sealed tubes may explain the contrasting correlations of bee and wasp reproduction with preyious year and current year rapeseed cover. Available floral resources during breeding season allow each female to lay more eggs in each tube, and to provision more pollen mixture for each larvae, which will result in a higher abundance in the next year, hence in a positive correlation between nesting ând previous year rapeseed cover. However, females may not necessarily seal more tubes even when more pollen resources are available because of the high cost of the nest plug (Rust 1993), hence the non-significant effect of current rapeseed cover on bee reproduction. Riedinger et al. (2015) showed that rapeseed has a year-to-year effect by promoting a higher solitary bee and wasp abundance the following year. Here we show that this higher abundance of solitary bees and wasps, which we did not measure directly, also translates into higher reproductive potential, an indirect piece of evidence that rapeseed promotes solitary bee and wasp populations (Fig. 5). This result was not completely expected, since the rapeseed blooming period is limited, and since its pollen may be of minor importance for larvae diet (Coudrain et al. 2016). Moreover, as a result of crop rotation, a high rapeseed cover one year may lead to a lack of floral resources in the landscape the following year. 

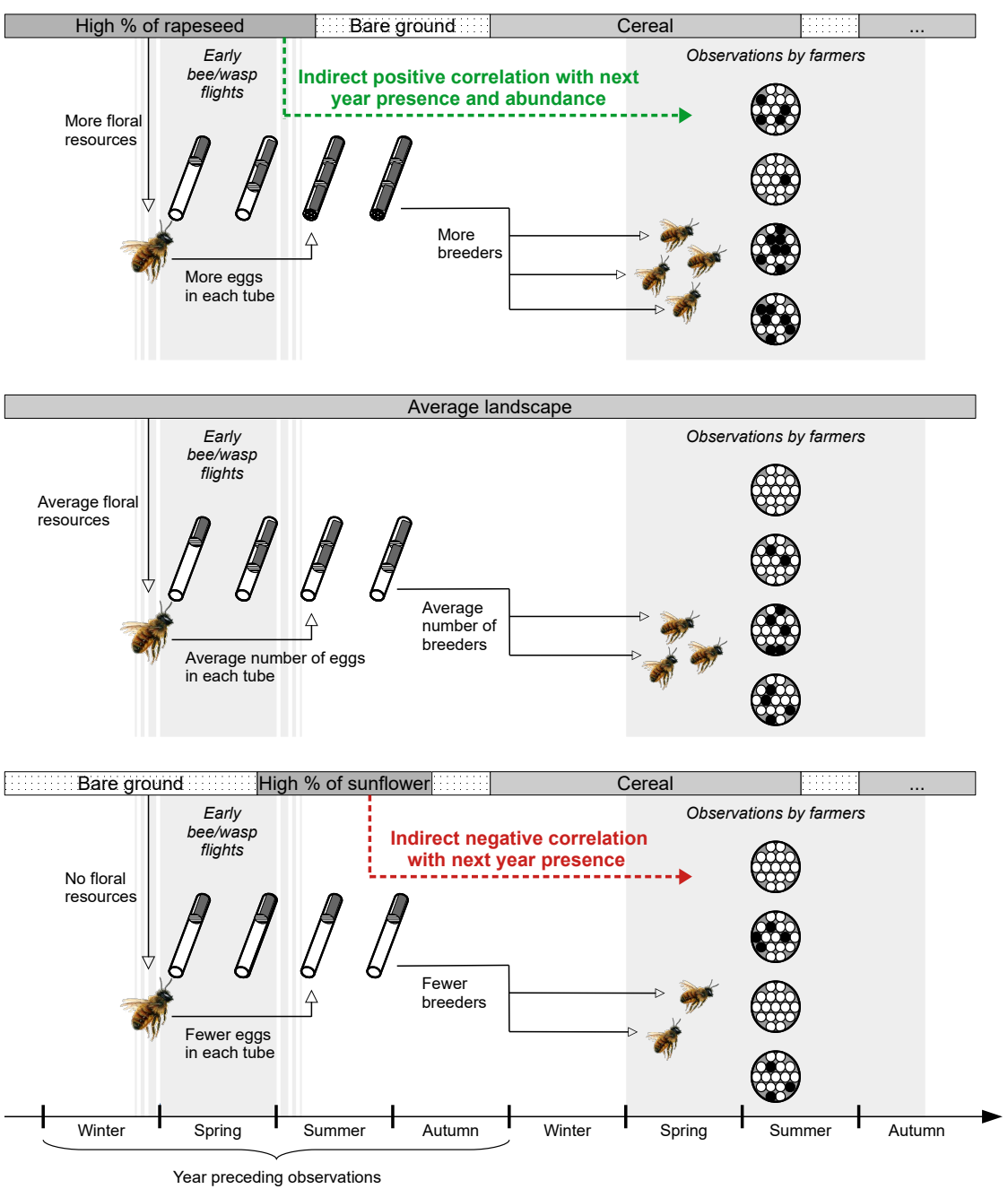

Fig. 5 Schematic summary of possible inter-annual effects of rapeseed (top) or sunflower (bottom) floral resources on solitary bee reproduction, as compared with an average landscape (middle). Osmia rufa drawing by Valerie Littlewood, used with permission.

Sunflower area had a more contrasting correlation with wild bee/wasp reproduction, depending on the type of sealing material analyzed. For mudsealed tubes the relation with previous-year resources was on the whole more negative than for rapeseed, whereas when counting all tubes the relation with current-year resources was positive. Unlike rapeseed that blooms in spring, sunflower is a summer crop. The different relationships with bee reproduction may confirm that mud-sealed tubes are mainly produced by solitary bees active 
in early spring, such as Osmia, which are known to pollinate spring-blooming crops (Bosch, Sgolastra, and Kemp 2008). Sunflower area was negatively correlated with next-year reproduction of pollinators using mud in the presence model in field crop edges. This negative correlation between sunflower field area in the previous year and the presence of mud-sealed nests may be understood according to the same logic of interpretation as the one adopted in the case of the effects of rapeseed. Since sunflower is a summer crop sown in April, a high cover leads to a lack of floral resources during the spring and may therefore reduce the number of breeders in the next year (Fig. 5). However, according to this hypothesis, the abundance, not only the presence, of mud-sealed tubes should also have been negatively correlated with sunflower field area in the previous year. Finally the dissimilarities between the effect of sunflower when all tubes vs. mud-sealed tubes only are considered suggest that on average species using sealing materials other than mud have later phenologies than species using mud and are positively affected by the resources provided by sunflower. Differences were observed on zero models only probably because mud-sealed tubes represent the majority of observations and drive the abundance data.

We found little correlation of bee and wasp reproduction with the area of MFCs growing simultaneously but the interactions between MFC cover in the current year and farming system were sometimes significant, in a surprising way. We expected local pesticide use intensity to have negative effects on nesting, and even to counteract the positive effects of MFC floral resources and semi-natural habitats as demonstrated for pest biological control (Ricci et al. 2019). Our analyses did not confirm these predictions, since farming system alone did not have any significant effect and conventional practices interacted positively with rapeseed resources (Fig. 3). Besides, some of these significant interactions tended to vanish when studying the total number of occupied nests instead of mud-sealed tubes. Again, these differences are consistent with the hypothesis of partly different spring and summer communities. One reason why we did not observe general negative effects of conventional farming may be related to our data not measuring the number of offspring directly: pesticide exposure might not reduce nesting, but only reduce offspring production and alter the sex-ratio (Stuligross and Williams 2020). However, these results are difficult to interpret because we lack information on practices at the landscape level, while some authors emphasize the need to combine both local and landscape levels when assessing the impacts of the intensity of farming practices (Carrié et al 2017).

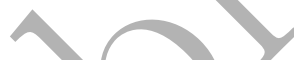

4.2 Importance of semi-natural elements and other permanent landscap features

Both for the probability of presence and abundance of sealed tubes, the area of permanent meadows in the buffer strongly promoted solitary bee and wasp reproduction. This is consistent with previous studies which showed that loss 
of semi-natural habitats, i.e. land uses that are minimally managed and not cultivated for arable crops, is one of the main drivers of pollinator decline (Ricketts et al. 2008; Tscharntke et al. 2012). As the dynamics of wild bee populations are mainly driven by the amount of nesting and floral resources (Lonsdorf et al. 2009), semi-natural areas help maintain bee populations (Carré et al. 2009; Tscharntke et al. 2012) by providing both nesting and food opportunities. Remaining permanent meadows may also be important to offset bee decline caused by meadow-to-crop conversion that occurred long ago (Provost et al. 2020). Moreover, these semi-natural habitats may decrease the negative effect of warmer temperature on bee populations (Papanikolaou et al. 2017) and buffer the harmful impacts of pesticides (Park et al. 2015).

In both our models however, there was no evidence of a positive effect of the proximity of hedgerows, except for the probability of nesting, regardless of sealing material, in field crops. This observation goes against our expectations, since it has been shown that abundance and diversity of wild bees are enhanced in field edges by hedgerows (Morandin and Kremen 2013). This result may be due to the fact that this parameter is reported by farmers, whose definition of a hedgerow may differ and may include different types of vegetation and different stages of the hedgerows (recently planted or older, more or less diversified). By contrast, our models evidenced a negative impact of the presence of a road. The amount of roads has already been shown to decrease bumblebee density (Kallioniemi et al. 2017), but road verges could also provide floral resources for wild bees (Henriksen and Langer 2013).

Semi-natural areas and mass-flowering crops do not have the same relative importance. In both zero models, the area of permanent meadows had a stronger positive effect than the area of rapeseed in the previous year. On the contrary, in both count models, the impact of rapeseed was slightly to substantially stronger. The presence of sealed tubes thus seems to depend more on semi-natural areas while their abundance seems to depend more on the resources provided by rapeseed. Neverthelèss, the permanent meadow area does not condition the positive effect of rapeseed: we tested the interaction between the two variables and we did not find any significant correlation (not shown). The presence of permanent meadows may be a important factor when a wild bee chooses where to build its nest, because some wild flowers in meadows are in bloom before rapeseed fields and thus are more attractive. Once the nest is built, rapeseed will provide a massive amount of pollen and nectar to pollinators active during its flowering period (such as Osmia), allowing each female to lay more eggs in each tube and thus increasing the number of breeders the following year.

\section{Conclusion: implications for pollinator conservation in} agricultural landscapes

Defining how agriculturally dominated landscapes can be optimized for wild bees remains a complex subject. Our study shows that solitary bee and wasp

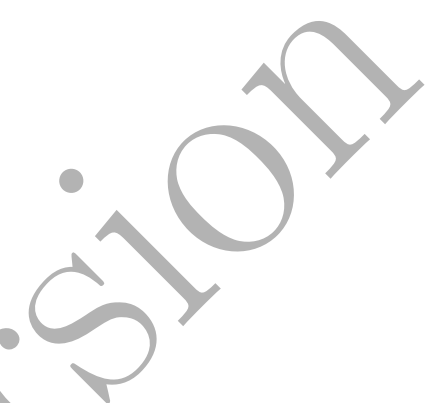


reproduction can be positively and durably affected by rapeseed cover. This crop provides a massive amount of floral resources at a period favorable for early wild bees. Moreover, our study confirms that permanent meadows are essential to promote solitary bee and wasp populations. The positive effect of rapeseed cover may hold only if enough food and nesting sites are available in adjacent natural habitats. Ricketts et al. (2008) showed that flower-visitor richness and visitation rate in croplands decline with distance from natural areas, and a lack of natural habitats can directly impact on crop yield (Garibaldi et al. 2011; Holzschuh et al. 2012). Protecting natural habitats near crop fields seems to be a key solution to secure natural supply of pollination service, and moderate covers of rapeseed may help to maintain solitary bee populations. However, rapeseed flowering period is short, thus pollinators still need floral resources from other crops and other semi-natural habitats (Martins et al. 2018), especially as we studied a small part of the solitary bee and wasp community. The use of rapeseed for promoting wild pollinators needs also to be viewed bearing in mind the heavy pesticide application on this crop.

\section{Acknowledgments}

We thank all farmers who provided observations from their fields, the FBO management team (Elodie Chauvet, Marion Demade, Marie Garnier, Marine Gérardin, Romain Julliard, Christophe Pinard, Nora Rouillier and Rose-Line Vermeersch) and the French Ministry of Agriculture, which supported the program. We also thank Adrien Perrard and three anonymous reviewers for their insightful comments and for shedding some light on the diversity of potential trap nest residents.

\section{Declarations}

Funding This research project was funded by the Crédit Agricole through sponsoring to O.B. and V.V.

Conflicts of interest All authors declare that they have no conflict of interests.

\section{Ethics approval Not applicable.}

Consent to participate Not applicable.

Consent for publication Not applicable.

Availability of data The data associated with this study will be available on Zenodo upon acceptance of the manuscript.

Code availability The $\mathrm{R}$ code used for statistical analyses will be made available on GitHub upon acceptance of the manuscript. 
Authors' contributions All authors contributed to the study conception and design. Data collection and analysis were performed by Victor Van der Meersch and Olivier Billaud. The first draft of the manuscript was written by Victor Van der Meersch and Emmanuelle Porcher, and all authors commented on previous versions of the manuscript. All authors read and approved the final manuscript.

\section{References}

Artz, Derek R., and Theresa L. Pitts-Singer. 2015. "Effects of Fungicide and Adjuvant Sprays on Nesting Behavior in Two Managed Solitary Bees, Osmia Lignaria and Megachile Rotundata." Edited by Nicolas Desneux. PLOS ONE 10 (8): e0135688. https://doi.org/10.1371/journal.pone.0135688.

Azpiazu, Celeste, Jordi Bosch, Elisa Viñuela, Piotr Medrzycki, Dariusz Teper, and Fabio Sgolastra. 2019. "Chronic Oral Exposure to Field-Realistic Pesticide Combinations via Pollen and Nectar: Effects on Feeding and Thermal Performance in a Solitary Bee." Scientific Reports 9 (1). https://doi.org/ 10.1038/s41598-019-50255-4.

Bailey, Samantha, Fabrice Requier, Benoit Nusillard, Stuart P. M. Roberts, Simon G. Potts, and Christophe Bouget. 2014. "Distance from Forest Edge Affects Bee Pollinators in Oilseed Rape Fields." Ecology and Evolution 4 (4): 370-80. https://doi.org/10.1002/ece3.924 Bartoń, Kamil. 2020. MuMIn: Multi-Model Inference. https://CRAN.Rproject.org/package=MuMIn.

Benton, Tim G., David M. Bryant, Lorna Cole, and Humphrey Q. P. Crick. 2002. "Linking Agricultural Practice to Insect and Bird Populations: A Historical Study over Three Decades." Journal of Applied Ecology 39 (4): 673-87. https://doi.org/10.1046/j.1365-2664.2002.00745.x.

Biddinger, Jacqueline L. AND Mullin, David J. AND Robertson. 2013. "Comparative Toxicities and Synergism of Apple Orchard Pesticides to Apis Mellifera (L.) and Osmia Cornifrons,(Radoszkowski)." PLOS ONE 8 (9): 1-6. https://doi.org/10.1371/journal.pone.0072587.

Biesmeijer, J. C., S. P. M. Roberts, M. Reemer, R. Ohlemüller, M. Edwards, T. Peeters, A. P. Schaffers, et al. 2006. "Parallel Declines in Pollinators and Insect-Pollinated Plants in Britain and the Netherlands." Science 313 (5785): 351-54. https://doi.org/10.1126/science.1127863.

Billaud, Olivier, Rose-Line Vermeersch, and Emmanuelle Porcher. 2020. "Citizen Science Involving Farmers as a Means to Document Temporal Trends in Farmland Biodiversity and Relate Them to Agricultural Practices." Journal of Applied Ecology. https://doi.org/10.1111/1365-2664.13746.

Bosch, Jordi, Fabio Sgolastra, and William P. Kemp. 2008. "6. Life Cycle Ecophysiology of Osmia Mason Bees Used as Crop Pollinators." In Bee Pollination in Agricultural Eco-Systems, 83-105. Oxford University Press. https: //doi.org/10.1093/acprof:oso/9780195316957.003.0006. 
Bretagnolle, Vincent, and Sabrina Gaba. 2015. "Weeds for Bees? A Review." Agronomy for Sustainable Development 35 (3): 891-909. https://doi. org/10.1007/s13593-015-0302-5.

Brooks, Mollie E., Kasper Kristensen, Koen J. van Benthem, Arni Magnusson, Casper W. Berg, Anders Nielsen, Hans J. Skaug, Martin Maechler, and Benjamin M. Bolker. 2017. "glmmTMB Balances Speed and Flexibility Among Packages for Zero-Inflated Generalized Linear Mixed Modeling." The $R$ Journal 9 (2): 378-400.https://journal.r-project.org/archive/2017/ RJ-2017-066/index.html

Burkle, Laura A., John C. Marlin, and Tiffany M. Knight. 2013. "PlantPollinator Interactions over 120 Years: Loss of Species, Co-Occurrence, and Function." Science 339 (6127): 1611-5. https://doi.org/10.1126/science. 1232728 .

Carré, Gabriel, Philip Roche, Rémy Chifflet, Nicolas Morison, Riccardo Bommarco, Jenn Harrison-Cripps, Kristin Krewenka, et al. 2009. "Landscape Context and Habitat Type as Drivers of Bee Diversity in European Annual Crops." Agriculture, Ecosystems and Environment 133 (1): 40-47. https:// doi.org/https://doi.org/10.1016/j.agee.2009.05.001.

Carrié, Romain, Andrieu, Emilie, Ouin, Annie and Steffan-Dewenter, Ingolf. 2017. "Interactive effects of landscape-wide intensity of farming practices and landscape complexity on wild bee diversity." Landscape Ecology 32: 16311642. https://doi.org/10.1007/s10980-017-0530-y.

Carrié, Romain, Johan Ekroos, and Henrik G. Smith. 2018. "Organio Farming Supports Spatiotemporal Stability in Species Richness of Bumblebees and Butterflies." Biological Conservation 227: 48-55. https://doi.org/https: //doi.org/10.1016/j.biocon.2018.08.022.

Cornes, Richard C., Gerard van der Schrier, Else J. M. van/den Besselaar, and Philip D. Jones. 2018. "An Ensemble Version of the E-Obs Temperature and Precipitation Data Sets." Journal of Geophysical Research: Atmospheres 123 (17): 9391-9409. https://doi.org/10.1029/2017JD028200.

Coudrain, Valérie, Sarah Rittinèr, Felix Herzog, Willy Tinner, and Martin H. Entling. 2016. "Landscape Distribution of Food and Nesting Sites Affect Larval Diet and Nest Size, but Not Abundance of Osmia Bicornis." Insect Science 23 (5): 746-53. https://doi.org/10.1111/1744-7917.12238.

Diekötter, Tim, Taku Kadoya, Franziska Peter, Volkmar Wolters, and Frank Jauker. 2010. "Oilseed Rape Crops Distort Plant-Pollinator Interactions." Journal of Applied Ecology 47 (1): 209-14. https://doi.org/https: //doi.org/10.1111/j.1365-2664.2009.01759.x.

Diekötter, Tim, Franziska Peter, Birgit Jauker, Volkmar Wolters, and Frank Jauker. 2014. "Mass-Flowering Crops Increase Richness of Cavity-Nesting Bees and Wasps in Modern Agro-Ecosystems." GCB Bioenergy 6 (3): 219-26. https //doi.org/10.1111/gcbb.12080.

Garibaldi, Lucas A, Luísa G Carvalheiro, Sara D Leonhardt, Marcelo A Aizen, Brett R Blaauw, Rufus Isaacs, Michael Kuhlmann, et al. 2014. "From Research to Action: Enhancing Crop Yield Through Wild Pollinators." Fron- 
tiers in Ecology and the Environment 12 (8): 439-47. https://doi.org/10. $1890 / 130330$

Garibaldi, Lucas A., Ingolf Steffan-Dewenter, Claire Kremen, Juan M. Morales, Riccardo Bommarco, Saul A. Cunningham, Luísa G. Carvalheiro, et al. 2011. "Stability of Pollination Services Decreases with Isolation from Natural Areas Despite Honey Bee Visits." Ecology Letters 14 (10): 1062-72. https://doi.org/10.1111/j.1461-0248.2011.01669.x.

Goulson, D., G. C. Lye, and B. Darvill. 2008. "Decline and Conservation of Bumble Bees." Annual Review of Entomology 53 (1): 191-208. https:// doi.org/10.1146/annurev.ento.53.103106.093454.

Hartig, Florian. 2020. DHARMa: Residual Diagnostics for Hierarchical (Multi-Level / Mixed) Regression Models.https://CRAN.R-project.org/package= DHARMa

Henriksen, Casper Ingerslev, and Vibeke Langer. 2013. "Road Verges and Winter Wheat Fields as Resources for Wild Bees in Agricultural Landscapes." Agriculture, Ecosystems \& Environment 173: 66-71.https://doi.org/https: //doi.org/10.1016/j.agee.2013.04.008

Holzschuh, Andrea, Matteo Dainese, Juan P. González-Varo, Sonja MudriStojnić, Verena Riedinger, Maj Rundlöf, Jeroen Scheper, et al. 2016. "MassFlowering Crops Dilute Pollinator Abundance in Agricultural Landscapes Across Europe." Ecology Letters 19 (10): 1228-36. https://doi.org/10.1111/ele. 12657.

Holzschuh, Andrea, Carsten F. Dormann, Teja Tscharntke, and Ingolf Steffan-Dewenter. 2012. "Mass-Flowering Crops Enhance Wild Bee Abundance." Oecologia 172 (2): 477-84. https://doi.org/10.1007/s00442-012$2515-5$.

Jackson, Heather Bird, and Lenore Fahrig. 2015. "Are Ecoløgists Conducting Research at the Optimal Scale?" Global Ecology and Biogeography 24 (1): 52-63. https://doi.org/10.1111/geb.12233.

Jauker, Frank, Birgit Bondarenko, Heiko C. Becker, and Ingolf SteffanDewenter. 2012. "Pollination Efficièncy of Wild Bees and Hoverflies Provided to Oilseed Rape." Agriculturaland Forest Entomology 14 (1): 81-87. https: //doi.org/10.1111/j.1461-9563.2011.00541.x

Jauker, Frank, Franziska Peter, Volkmar Wolters, and Tim Diekötter. 2012. "Early Reproductive Benefits of Mass-Flowering Crops to the Solitary Bee Osmia Rufa Outbalance Post-Flowering Disadvantages." Basic and Applied Ecology 13 (3): 268-76. https://doi.org/https://doi.org/10.1016/j.baae. 2012.03 .010

Joshi, Neelendra K., Mark Otieno, Edwin G. Rajotte, Shelby J. Fleischer, and David J. Biddinger. 2016. "Proximity to Woodland and Landscape Structure Drives Pollinator Visitation in Apple Orchard Ecosystem." Frontiers in Ecology and Evolution 4: 38. https://doi.org/10.3389/fevo.2016.00038.

Kallioniemi, Eveliina, Jens Åström, Graciela M. Rusch, Sondre Dahle, Sandra Åström, and Jan Ove Gjershaug. 2017. "Local Resources, Linear Elements and Mass-Flowering Crops Determine Bumblebee Occurrences in Moderately 
Intensified Farmlands." Agriculture, Ecosystems \& Environment 239: 90-100. https://doi.org/https://doi.org/10.1016/j.agee.2016.12.039

Klein, Alexandra-Maria, Bernard E Vaissière, James H Cane, Ingolf SteffanDewenter, Saul A Cunningham, Claire Kremen, and Teja Tscharntke. 2007. "Importance of Pollinators in Changing Landscapes for World Crops." Proceedings of the Royal Society B: Biological Sciences 274 (1608): 303-13. https : //doi.org/10.1098/rspb.2006.3721.

Le Féon, Violette, Françoise Burel, Rémy Chifflet, Mickaël Henry, Agnès Ricroch, Bernard E. Vaissière, and Jacques Baudry. 2013. "Solitary Bee Abundance and Species Richness in Dynamic Agricultural Landscapes." Agriculture, Ecosystems and Environment 166: 94-101. https://doi.org/https: //doi.org/10.1016/j.agee.2011.06.020

Leifeld, Philip. 2013. "texreg: Conversion of Statistical Model Output in R to LaTeX and HTML Tables." Journal of Statistical Software 55 (8): 1-24. http://www.jstatsoft.org/v55/i08/.

Linsley, E. Gorton. 1958. "The Ecology of Solitary Bees." Hilgardia 27 (19): 543-99. https://doi.org/10.3733/hilg.v27n19p543

Lonsdorf, Eric, Claire Kremen, Taylor Ricketts, Rachael Winfree, Neal Williams, and Sarah Greenleaf. 2009. "Modelling pollination services across agricultural landscapes." Annals of Botany 103 (9): 1589-1600. https://doj. org/10.1093/aob/mcp069.

Lüdecke, Daniel. 2018. "Ggeffects: Tidy Data Frames of Marginal Effects from Regression Models." Journal of Open Source Software 3 (26): 772. https : //doi.org/10.21105/joss.00772

Lüdecke, Daniel, Dominique Makowski, Philip Waggoner, and Indrajeet Patil. 2020. Performance: Assessment of Regression Models Performance. https: //CRAN.R-project.org/package=performance.

MacIvor, J. Scott, and Laurence Packer. 2015. 'Bee Hotels' as Tools for Native Pollinator Conservation: A Rremature Verdict?" Edited by Fabio S. Nascimento. PLOS ONE 10 (3): e0122126. https://doi.org/10.1371/ journal.pone.0122126.

Mallinger, Rachel E., and Claudio Gratton. 2015. "Species Richness of Wild Bees, but Not the Use of Managed Honeybees, Increases Fruit Set of a Pollinator-Dependent Crop." Journal of Applied Ecology 52 (2): 323-30. https://doi.org/10.1111/1365-2664.12377.

Martins, Kyle T., Cécile H. Albert, Martin J. Lechowicz, and Andrew Gonzalez. 2018. "Complementary Crops and Landscape Features Sustain Wild Bee Communities." Ecological Applications 28 (4): 1093-1105. https://doi. org/10.1002/eap.1713

Michener, Charles. 2007. The Bees of the World. Baltimore: Johns Hopkins University Press. https://jhupbooks.press.jhu.edu/title/bees-world

Morandin, Lora A., and Claire Kremen. 2013. "Hedgerow Restoration Promotes Pollinator Populations and Exports Native Bees to Adjacent Fields." Ecological Applications 23 (4): 829-39. https://doi.org/10.1890/12-1051. 1. 
Odanaka, Katherine A., and Sandra M. Rehan. 2020. "Wild Bee Distribu2 tion Near Forested Landscapes Is Dependent on Successional State." Forest Ecosystems 7 (1). https://doi.org/10.1186/s40663-020-00241-4

Ollerton, Jeff, Rachael Winfree, and Sam Tarrant. 2011. "How Many Flowering Plants Are Pollinated by Animals?" Oikos 120 (3): 321-26. https: //doi.org/10.1111/j.1600-0706.2010.18644.x.

Papanikolaou, Alexandra D., Ingolf Kühn, Mark Frenzel, and Oliver Schweiger. 2017. "Semi-Natural Habitats Mitigate the Effects of Temperature Rise on Wild Bees." Journal of Applied Ecology 54 (2): 527-36. https://doi.org/ 10.1111/1365-2664.12763.

Park, Mia G., E. J. Blitzer, Jason Gibbs, John E. Losey, and Bryan N. Danforth. 2015. "Negative Effects of Pesticides on Wild Bee Communities Can Be Buffered by Landscape Context." Proceedings of the Royal Society B: Biological Sciences 282 (1809): 20150299. https://doi.org/10.1098/rspb. 2015.0299.

Pebesma, Edzer. 2018. "Simple Features for R: Standardized Support for Spatial Vector Data." The R Journal 10 (1): 439-46. https://doi.org/10. 32614/RJ-2018-009.

Pereira-Peixoto, Maria Helena, Gesine Pufal, Celso Feitosa Martins, and Alexandra-Maria Klein. 2014. "Spillover of Trap-Nesting Bees and Wasps in an Urban-rural Interface." Journal of Insect Conservation 18 (5): 815-26. https://doi.org/10.1007/s10841-014-9688-7.

Potts, Joanne M., and Jane Elith. 2006. "Comparing Species Abundance Models." Ecological Modelling 199 (2): 153-63. https://doi.org/https:// doi.org/10.1016/j.ecolmodel.2006.05.025.

Potts, Simon G., Jacobus C. Biesmeijer, Claire Kremen, Peter Neumann, Oliver Schweiger, and William E. Kunin. 2010. "Global Pollinator Declines: Trends, Impacts and Drivers." Trends in Ecology and Evolution 25 (6): 345-53. https://doi.org/https://doi.org/10.1016/j.tree.2010.01.007

Potts, Simon G., Betsy Vulliamy, Amots Dafni, Gidi Ne'eman, and Pat Willmer. 2003. "Linking Bees and Flowers: How Do Floral Communities Structure Pollinatore Communities?" Ecology 84 (10): 2628-42. https://doi.org/ 10.1890/02-0136.

Provost, Gaëtane Le, Isabelle Badenhausser, Cyrille Violle, Fabrice Requier, Marie D’Ottavio, Marilyn Roncoroni, Louis Gross, and Nicolas Gross. 2020. "Grassland-to-Crop Conversion in Agricultural Landscapes Has Lasting Impact on the Trait Diversity of Bees." Landscape Ecology, October. https: //doi.org/10.1007/s10980-020-01141-2.

R Core Team. 2020. R: A Language and Environment for Statistical Computing. Vienna, Austria: $\mathrm{R}$ Foundation for Statistical Computing. https: //www.R-project.org/.

Ricci, B., C. Lavigne, A. Alignier, S. Aviron, L. Biju-Duval, J. C. Bouvier, J.-P. Choisis, et al. 2019. "Local Pesticide Use Intensity Conditions Landscape Effects on Biological Pest Control." Proceedings of the Royal Society B: Biological Sciences 286 (1904): 20182898. https://doi.org/10.1098/rspb.2018. 2898. 
Ricketts, Taylor H., James Regetz, Ingolf Steffan-Dewenter, Saul A. Cunningham, Claire Kremen, Anne Bogdanski, Barbara Gemmill-Herren, et al. 2008. "Landscape Effects on Crop Pollination Services: Are There General Patterns?" Ecology Letters 11 (5): 499-515. https://doi.org/10.1111/j.14610248.2008.01157.x.

Riedinger, Verena, Oliver Mitesser, Thomas Hovestadt, Ingolf Steffan-Dewenter, and Andrea Holzschuh. 2015. "Annual Dynamics of Wild Bee Densities: Attractiveness and Productivity Effects of Oilseed Rape." Ecology 96 (5): 135160. https://doi.org/10.1890/14-1124.1.

Rollin, Orianne, Vincent Bretagnolle, Axel Decourtye, Jean Aptel, Nadia Michel, Bernard E. Vaissière, and Mickaël Henry. 2013. "Differences of Floral Resource Use Between Honey Bees and Wild Bees in an Intensive Farming System." Agriculture, Ecosystems and Environment 179: 78-86. https://doi. org/https://doi.org/10.1016/j.agee.2013.07.007.

RStudio Team. 2019. RStudio: Integrated Development Environment for $R$. Boston, MA: RStudio, Inc. http://www.rstudio.com/.

Rundlöf, Maj, Georg K. S. Andersson, Riccardo Bommarco, Ingemar Fries, Veronica Hederström, Lina Herbertsson, Ove Jonsson, et al. 2015. "Seed Coating with a Neonicotinoid Insecticide Negatively Affects Wild Bees." Nature 521 (7550): 77-80. https://doi.org/10.1038/nature14420

Rust, Richard W. 1993. "Cell and Nest Construction Costs in Two CayityNesting Bees (Osmia lignaria propinqua and Osmia ribifloris biedermannii) (Hymenoptera: Megachilidae)." Annals of the Entomological Society of America 86 (3): 327-32. https://doi.org/10.1093/aesa/86.3.327.

Sánchez-Bayo, Francisco, and Kris A. G. Wyckhuys. 2019. "Worldwide Decline of the Entomofauna: A Review of Its Drivers." Biological Conservation 232: 8-27. https://doi.org/https://doi.org/10.1016/j.biocon. 2019.01.020.

Sgolastra, Fabio, Piotr Medrzycki, Laura Bortolotti, Maria Teresa Renzi, Simone Tosi, Gherardo Bogo, Dariusz Teper, Claudio Porrini, Roberto MolownyHoras, and Jordi Bosch. 2017. "Synergistic Mortality Between a Neonicotinoid Insecticide and an Ergosterol-Biosynthêsis-Inhibiting Fungicide in Three Bee Species." Pest Management Science 73 (6): 1236-43. https://doi.org/10. 1002/ps. 4449 .

Shaw, Rosalind F., Benjamin B. Phillips, Toby Doyle, Judith K. Pell, John W. Redhead, Joanna Savage, Ben A. Woodcock, James M. Bullock, and Juliet L. Osborne. 2020. "Mass-Flowering Crops Have a Greater Impact Than SemiNatural Habitat on Crop Pollinators and Pollen Deposition." Landscape Ecology 35 (2): 513-27,https://doi.org/10.1007/s10980-019-00962-0

Steffan-Dewenter, Ingolf. 2002. "Landscape Context Affects Trap-Nesting Bees, Wasps, and Their Natural Enemies." Ecological Entomology 27 (5): 63137. https://doi.org/10.1046/j.1365-2311.2002.00437.x

Steffan-Dewenter, Ingolf, and Kathleen Leschke. 2003. "Effects of Habitat Management on Vegetation and Above-Ground Nesting Bees and Wasps of Orchard Meadows in Central Europe." Biodiversity and Conservation 12 (9): 1953-68. https://doi.org/10.1023/a:1024199513365. 
Stuligross, Clara, and Neal M. Williams. 2020. "Pesticide and Resource 774 Stressors Additively Impair Wild Bee Reproduction." Proceedings of the Royal Society B: Biological Sciences 287 (1935): 20201390. https://doi.org/10. 1098/rspb.2020.1390.

Tscharntke, Teja, Jason M. Tylianakis, Tatyana A. Rand, Raphael K. Didham, Lenore Fahrig, Péter Batáry, Janne Bengtsson, et al. 2012. "Landscape Moderation of Biodiversity Patterns and Processes - Eight Hypotheses." Biological Reviews 87 (3): 661-85. https://doi.org/10.1111/j.1469185X.2011.00216.x.

Vanbergen, Adam J, and the Insect Pollinators Initiative. 2013. "Threats to an Ecosystem Service: Pressures on Pollinators." Frontiers in Ecology and the Environment 11 (5): 251-59. https://doi.org/10.1890/120126

Vicens, Narcís, and Jordi Bosch. 2000. "Weather-Dependent Pollinator Activity in an Apple Orchard, with Special Reference to Osmia cornuta and Apis mellifera (Hymenoptera: Megachilidae and Apidae)." Environmental Entomology 29 (3): 413-20. https://doi.org/10.1603/0046-225X-29.3.413.

Woodcock, B. A., J. M. Bullock, R. F. Shore, M. S. Heard, M. G. Pereira, J. Redhead, L. Ridding, et al. 2017. "Country-Specific Effects of Neonicotinoid Pesticides on Honey Bees and Wild Bees." Science 356 (6345): 1393-5. https: //doi.org/10.1126/science.aaa1190.

Woodcock, Ben A., Nicholas J. B. Isaac, James M. Bullock, David B. Roy, David G. Garthwaite, Andrew Crowe, and Richard F. Pywell. 2016. "Impacts of Neonicotinoid Use on Long-Term Population Changes in Wild Bees in Eng-

land." Nature Communications 7 (1).https://doi.org/10.1038/ncomms12459.

Zurbuchen, Antonia, Lisa Landert, Jeannine Klaiber, Andreas Müller, Silke Hein, and Silvia Dorn. 2010. "Maximum Foraging Ranges in Solitary Bees: Only Few Individuals Have the Capability to Cover Long Foraging Distances." Biological Conservation 143 (3): 669-76. https://doi.org/https://doi.org/ 10.1016/j.biocon.2009.12.003. 
Appendix A : variables included in full models

Table 2 Variables included in full models.

\begin{tabular}{lll}
\hline Type & Name & Source \\
\hline \multirow{5}{*}{ Local } & Farming system (in field crop model) \\
& Type of meadow (in meadow model) \\
& Young hedgerow \\
& Old hedgerow \\
& Grassy strip \\
& Road \\
& Woody margin \\
& Ditch
\end{tabular}


Appendix B : variance inflation factors

Table 3 Variance inflation factors for solitary bee models, obtained with the performance package (Lüdecke, Makowski, Waggoner, \& Patil, 2020.

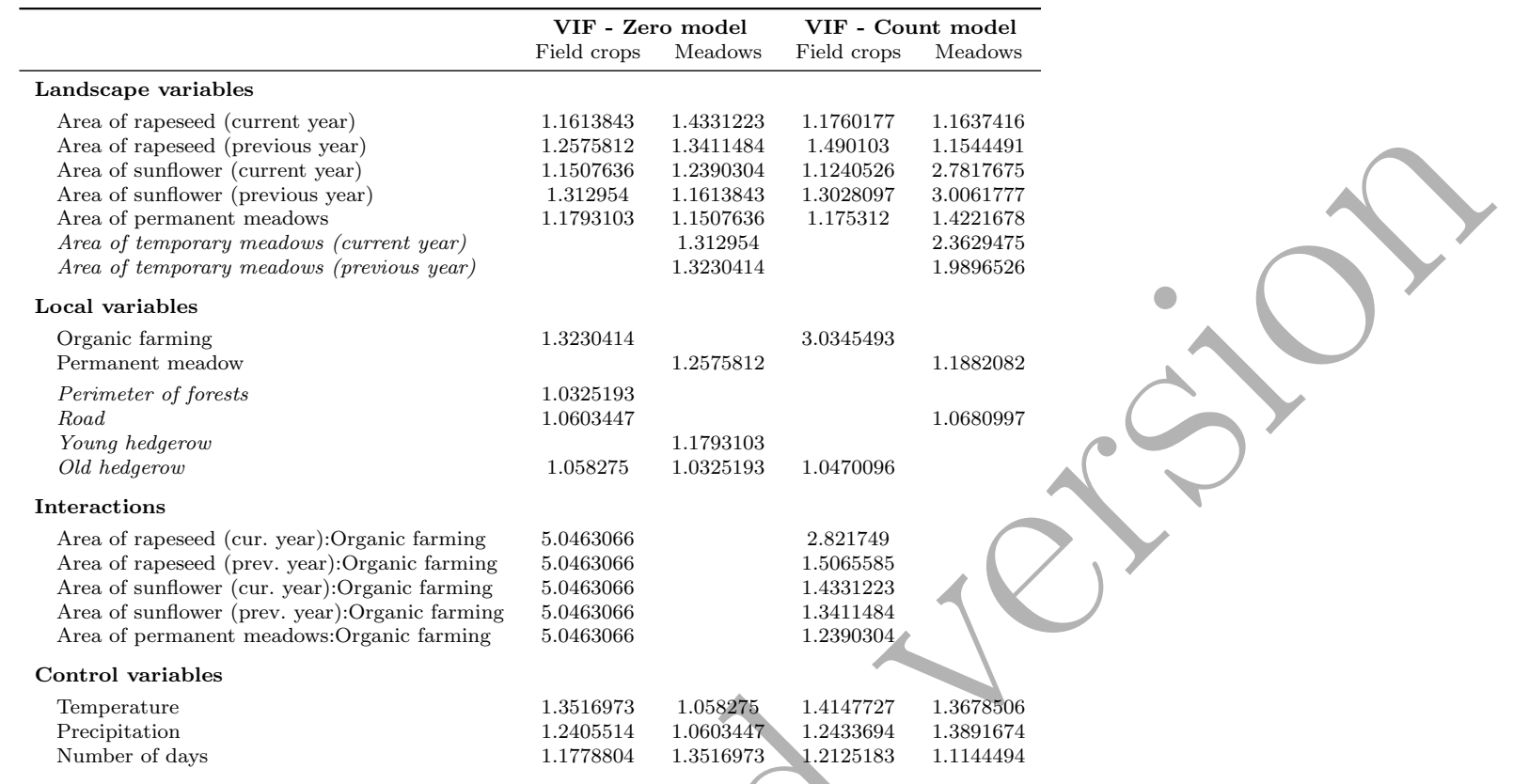


Appendix C : residual diagnostics
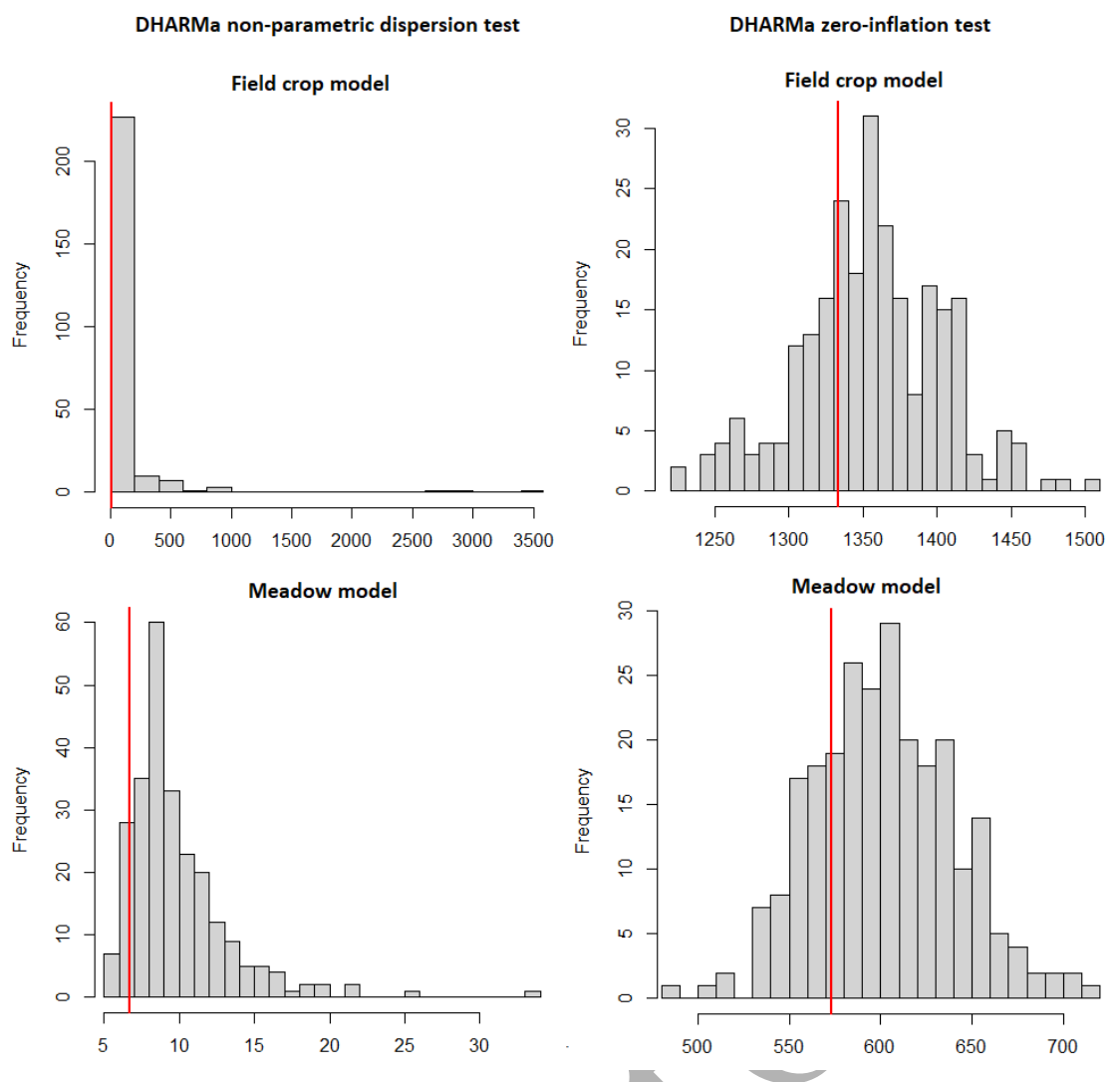

Fig. 6 Residual diagnostics for solitary bee models, obtained with the DHARMa package (Hartig, 2020). Grey bars are simulated values, the red line is the fitted model.

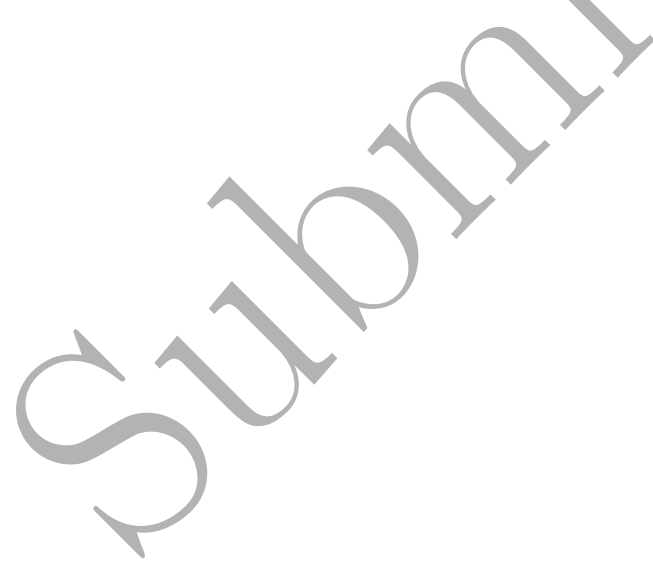




\section{Appendix D : Durbin-Watson tests}

To detect the presence of temporal autocorrelation in the residuals, we applied the Durbin Watson test to the sites that were monitored at least three times in the year. Thus, we could test 393 site/year couples in our field crop edge model and 174 site/year couples in our meadow edge model.
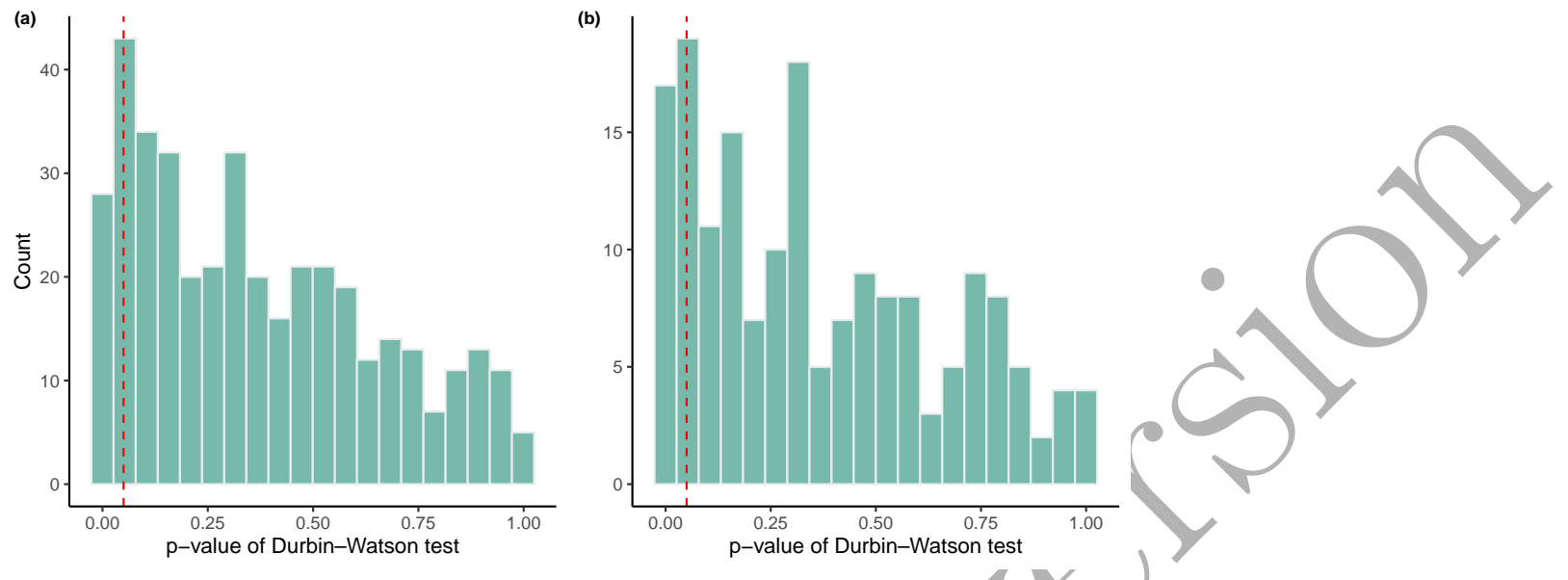

Fig. 7 Distribution of Durbin-Watson test p-values, for residuals of (a) field crop edge model or (b) meadow edge model. Red dashed line is the 0.05 threshold.

In our field crop edge model, a total of 51 site/year couples (13\%) have a p-value lower than 0.05 . In our meadow edge model, a total of 27 site/year couples $(15.5 \%)$ have a p-value lower than 0.05 . 


\section{Appendix E : alternative models}

Table 4 Comparison of hurdle model outputs examining the relationship between the presence of tubes ("Zero model") or their abundance conditional on presence ("Count model") and environmental variables, for trap nests set up in field crop edges. The table shows the parameter estimates, with standard errors in parentheses. Parameters with a p-value $<0.05$ are reported in bold. All variables were standardized and centered.

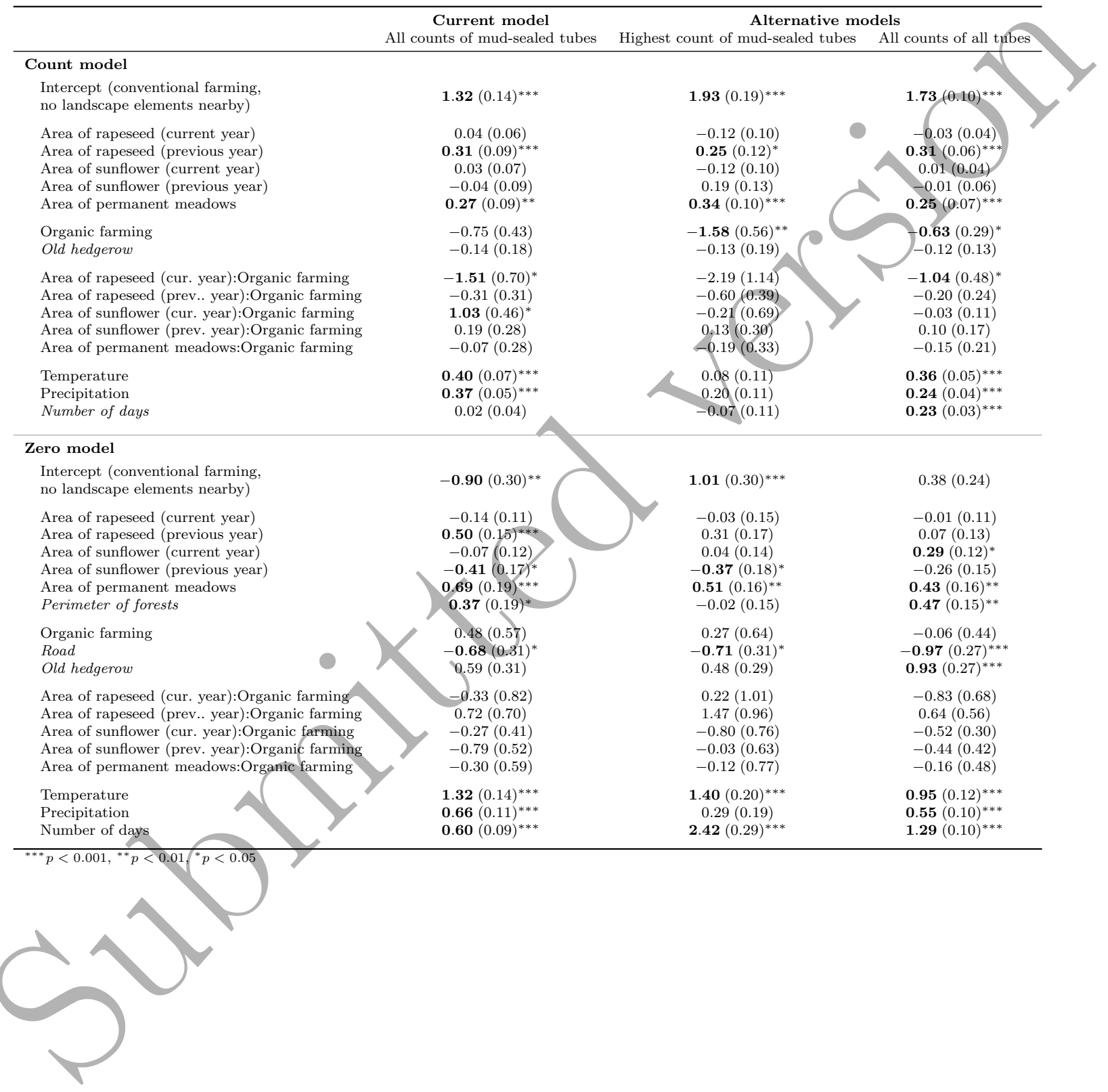


Table 5 Comparison of hurdle model outputs examining the relationship between the presence of tubes ("Zero model") or their abundance conditional on presence ("Count model") and environmental variables, for trap nests set up in meadows edges. The table shows the parameter estimates, with standard errors in parentheses. Parameters with a p-value $<0.05$ are reported in bold. All variables were standardized and centered.

\begin{tabular}{|c|c|c|c|}
\hline & \multirow{2}{*}{$\begin{array}{c}\text { Current model } \\
\text { All counts of mud-sealed tubes }\end{array}$} & \multicolumn{2}{|c|}{ Alternative models } \\
\hline & & Highest count of mud-sealed tubes & All counts of all tubes \\
\hline \multicolumn{4}{|l|}{ Count model } \\
\hline $\begin{array}{l}\text { Intercept (temporary meadow, } \\
\text { no landscape elements nearby) }\end{array}$ & $1.63(0.20)^{* * *}$ & $1.93(0.29)^{* * *}$ & $1.91(0.18)^{* * *}$ \\
\hline Area of rapeseed (current year) & $-0.04(0.06)$ & $-0.15(0.13)$ & $0.03(0.06)$ \\
\hline Area of rapeseed (previous year) & $0.24(0.09)^{* *}$ & $0.27(0.12)^{*}$ & $0.16(0.08)^{*}$ \\
\hline Area of sunflower (current year) & $0.10(0.16)$ & $0.19(0.27)$ & $\mathbf{0 . 1 7}(0.09)^{*}$ \\
\hline Area of sunflower (previous year) & $-0.10(0.16)$ & $-0.16(0.22)$ & $-0.15(0.10)$ \\
\hline Area of permanent meadows & $0.11(0.11)$ & $0.12(0.13)$ & $0.10(0.10)$ \\
\hline Area of temporary meadows (current year) & $-0.40(0.16)^{*}$ & $-0.35(0.20)$ & $-0.25(0.14)$ \\
\hline Area of temporary meadows (previous year) & $\mathbf{0 . 3 0}(0.15)^{*}$ & $0.33(0.18)$ & $0.12(0.14)$ \\
\hline $\begin{array}{l}\text { Permanent meadow } \\
\text { Road }\end{array}$ & $-0.01(0.18)$ & $\begin{array}{c}0.18(0.25) \\
-0.37(0.25)\end{array}$ & $\begin{array}{r}-0.06(0.16) \\
-0.51(0.19)^{* *}\end{array}$ \\
\hline Road & $-\mathbf{0 . 5 0}(0.20)^{*}$ & $-0.37(0.25)$ & \\
\hline Temperature & $0.24(0.10)^{*}$ & $0.29(0.17)$ & $0.12(0.09)$ \\
\hline Precipitation & $\mathbf{0 . 2 5}(0.09)^{* * *}$ & $0.22(0.16)$ & $0.26(0.08)^{* *}$ \\
\hline Number of days & $0.18(0.06)^{* *}$ & $0.16(0.18)$ & $\mathbf{0 . 2 4}(0.05)^{* * *}$ \\
\hline \multicolumn{4}{|l|}{ Zero model } \\
\hline $\begin{array}{l}\text { Intercept (temporary meadow, } \\
\text { no landscape elements nearby) }\end{array}$ & $-\mathbf{1 . 7 2}(0.59)^{* *}$ & 88 & $-0.24(0.45)$ \\
\hline Area of rapeseed (current year) & $0.31(0.20)$ & $0.19(0.30)$ & $0.18(0.17)$ \\
\hline Area of rapeseed (previous year) & $0.13(0.29)$ & $0.06(0.25)$ & $0.04(0.24)$ \\
\hline Area of sunflower (current year) & $-0.35(0.30)$ & $-0.32(0.35)$ & $0.02(0.21)$ \\
\hline Area of sunflower (previous year) & $-0.16(0.38)$ & $-0.15(0.30)$ & $-0.33(0.29)$ \\
\hline Area of permanent meadows & $1.03(0.38)^{* * *}$ & $0.64(0.25)^{*}$ & $\mathbf{0 . 7 5}(0.29)^{* * *}$ \\
\hline Area of temporary meadows (current year) & $1.15(0.46)^{*}$ & $0.37(0.32)$ & $0.50(0.38)$ \\
\hline Area of temporary meadows (previous year) & $-\mathbf{1 . 0 9}(0.49)^{*}$ & $-0.22(0.32)$ & $-0.56(0.40)$ \\
\hline Permanent meadow & $0.51(0.40)$ & $-0.31(0.42)$ & $0.48(0.36)$ \\
\hline Young hedgerow & $1.16(0.66)$ & $0.08(0.59)$ & $0.43(0.53)$ \\
\hline Old hedgerow & $0.41(0.62)$ & $0.48(0.42)$ & $0.59(0.49)$ \\
\hline Temperature & & $0.97(0.28)^{* * *}$ & $1.81(0.27)^{* * *}$ \\
\hline Precipitation & 1.44 & $0.04(0.28)$ & $1.10(0.23)^{* * *}$ \\
\hline Number of days & & $2.10(0.35)^{* * *}$ & $1.38(0.16)^{* * *}$ \\
\hline \multicolumn{4}{|l|}{${ }^{* * *} p<0.001,{ }^{* *} p<0.01,{ }^{*} p<0.05$} \\
\hline
\end{tabular}

